\section{FREE ONLINE TELEMEDICINE COURSE}

Airedale NHS Foundation Trust and Western Sussex NHS Foundation Trust, as part of a 'Better Training Better Care' pilot sponsored by Health Education England, have joined forces with Virtual College to develop a free online training course: An Introduction to Telemedicine.

Telemedicine enables direct video communications between healthcare professionals, patients and

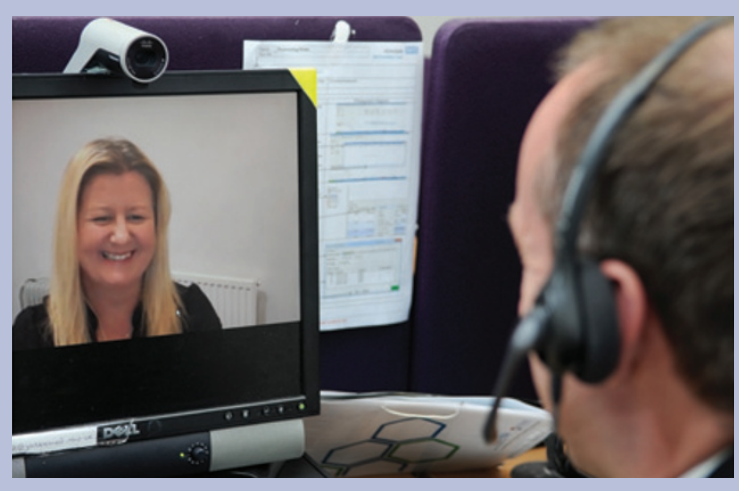

their carers. Airedale Hospital has been using telemedicine for direct patient care services since 2006.

The course aims to raise awareness of the opportunities for delivering healthcare differently and more efficiently, demonstrating some of the possible uses of telemedicine in different clinical and educational settings.

The free online course is aimed at all clinicians working across primary or secondary care settings along with their management teams. It highlights some new ways of working using telemedicine to support improvements in clinical safety and quality.

The course includes a section on how to conduct effective telemedicine consultations. In addition to looking at the common telemedicine functionality, factors such as clinical and information governance, pathway redesign and the uses of telemedicine in educational and training scenarios are considered promoting the practical uses of telemedicine as a clinical training and supervision tool.

Telemedicine can help avoid unnecessary visits and admissions to hospital, reduce the length of stay for patients admitted to hospital and is also beneficial in supporting care outside hospital.

The course conforms to CPD guidelines and is offered free of charge to those working within NHS organisations. Go to https:// telemedicine.healthcareea.co.uk/.

\section{HELPING YOU LOOK AFTER THE IMPORTANT THINGS IN LIFE}

Dentists' Provident have been the leading provider of income protection insurance to dentists in the UK and Ireland for over 100 years.

You can benefit from Dentists' Provident's in-depth experience of developing the most appropriate income protection solution at every stage of your personal and professional life. Their plans can be customised, giving you the choice of how to protect yourself against the financial consequences of illness or injury. Members also benefit from Dentists' Provident's ethical approach to claims, and personal UK-based customer service.

Dentists' Provident are a mutual organisation, so with no shareholders they exist solely for the benefit of their 13,500 members. On top of protection insurance, members also have the opportunity to share in any surpluses Dentists' Provident make, with a bonus account available on retirement.

For more information, call 020 7400 5710, email memberservices@dentistsprovident.co.uk or visit www.dentistsprovident.co.uk.

\title{
PROVIDE LIMITED TREATMENT OUTCOME ORTHODONTICS
}

Oralign Ltd helps dentists meet patient demand for limited treatment outcome orthodontics (LTO). This new concept provides specialist orthodontic support throughout treatment, safeguarding against unexpected tooth movement and unforeseen difficulties.

Oralign also offer GDPs highly intensive hands-on training courses free of charge (for a limited time only), to help you integrate this treatment into your service offering. Areas covered include: interproximal reduction and bracket bonding for fixed appliances; intra oral and extra oral photography; understanding which cases to tackle and which to refer; and presentation techniques to improve patient uptake. Oralign Ltd also provides an exclusive patient finance package.

Visit www.oralign.co.uk.

\section{THE FASTEST GROWING DENTURE CARE BRAND}

Poligrip will be on TV screens this summer as part of a $£ 2.7$ million media campaign. The Poligrip for Partials campaign is aimed at educating partial denture wearers on how to avoid further tooth loss by raising awareness of the Poligrip for Partials range launched last year.

The TV campaign focuses on the damage that partial dentures can cause to natural teeth and how important it is to protect them, especially since partial denture wearers are almost twice as likely to lose another tooth than non-partial wearers. The advert confronts toothloss in a touching manner by illustrating relatable moments in life that everyone can engage with, mentioning that you may lose your mobile phone or a pair of socks at some point in life, but you want to avoid losing another tooth. It also shows the significance of caring for partial dentures properly by using specially formulated products as part of an oral care routine.

The TV campaign will be supported with print and online advertising. The Poligrip portfolio includes a range of clinically proven and efficacious products to improve life with dentures and provide wearers with the confidence to engage more fully in life. Poligrip is sold throughout multiple retailers and pharmacies.

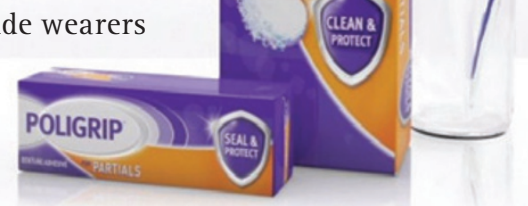

Care for your partial. Help protect your natural teeth. As part of a good oral care routine. www.poligrip-partials.co.uk 